\title{
Clinical Utility Gene Card for hereditary angioedema with normal C1 inhibitor (HAEnC1)
}

\author{
Christiane Stieber ${ }^{1,2,3}$, Sven Cichon ${ }^{4}$, Markus Magerl ${ }^{5}$ and Markus M Nöthen ${ }^{1,2,3}$ \\ European Journal of Human Genetics (2017) 25, doi:10.1038/ejhg.2017.104; published online 5 July 2017
}

\section{DISEASE CHARACTERISTICS}

1.1 Name of the disease (synonyms)

Hereditary angioedema type III (HAE-III)

Estrogen-related hereditary angioedema

Hereditary angioedema with factor XII mutations (FXII-HAE)

Hereditary angioedema of unknown origin (U-HAE)

\subsection{OMIM\# of the disease}

610618

1.3 Name of the analysed genes or DNA/chromosome segments Coagulation factor XII; Hageman factor; F12; chromosome 5q.35.2$\mathrm{q} 35.3$

\subsection{OMIM\# of the gene(s)}

610619

\subsection{Mutational spectrum}

To date, four disease-causing variants in F12 have been reported (ClinVar database https://www.ncbi.nlm.nih.gov/clinvar/).

The missense variants NG_007568.1(NM_000505.3):c.983C > A;p. Thr328Lys and NG_007568.1(NM_000505.3):c.983C > G;p.Thr328 Arg affect the threonine residue at position 328 of the protein. ${ }^{1,2}$ The p.Thr328Lys variant accounts for the large majority of variantpositive cases reported to date. p.Thr328Lys has been described in patients/families from various ethnic backgrounds. These ethnicities include Arabian; ${ }^{3,4}$ Australian; ${ }^{5}$ Brazilian, ${ }^{6}$ British; ${ }^{7}$ French;, ${ }^{1,8,9}$ German; ${ }^{1,2,10}$ Italian; ${ }^{11-13,}$ Jewish; ${ }^{3}$ and Spanish. ${ }^{14-16,}$ Haplotype studies of German, French, British, Italian, and Brazilian families have suggested a common founder. ${ }^{1,6,7,13}$ The p.Thr328Lys variant has been reported in a single German family. ${ }^{2}$ Functional studies have demonstrated that the mutant proteins are defective in terms of mucin-type Thr309-linked glycosylation. ${ }^{17}$ In these experiments, the loss of glycosylation led to increased contact-mediated autoactivation of zymogen FXII, resulting in excessive activation of the bradykininforming kallikrein-kinin pathway. In contrast, FXII-driven coagulation and the ability of C1-esterase inhibitor to bind and inhibit activated FXII were unaffected. Recent studies confirmed these findings, and showed that the change in protein glycosylation introduced new sites for potential cleavage. ${ }^{18}$ The variants caused accelerated FXII activation by plasmin, thereby interrupting the balance between activation and inhibition of the contact system in solution. As a result, the FXIImutants escaped Clinh inactivation during activation by plasmin. These results suggest that: (i) the plasminogen system and the contact activation system are functionally linked; and (ii) in HAEnC1 patients, an increased potential of plasminogen activation can prime plasma for excessive bradykinin production.

In addition to the two missense variants, one deletion and one duplication have been reported in single families. The NG_007568.1 (NM_000505.3):c.971_1018+24del;p.Lys324_Ala340delinsThr variant is a deletion of 72 base pairs (bp). ${ }^{19}$ This deletion causes a loss of $48 \mathrm{bp}$ of exon 9 (coding amino acids 324 to 340 ) and 24 bp of intron 9. The deletion includes the authentic donor splice site of exon 9. The variant NG_007568.1(NM_000505.3):c.894_911dup;p.(Gln300_Thr305dup) is a duplication of $18 \mathrm{bp} \cdot{ }^{20}$ This duplication causes the repeat of 6 amino acids. As with the missense variants, the duplication and the deletion affect the proline-rich region, which suggests similar functional consequences. $^{21}$ For the deletion variant, the anticipated functional consequences have been demonstrated experimentally. ${ }^{18}$ For the duplication, no functional investigations have yet been performed.

\subsection{Analytical methods}

A diagnosis of HAEnC1 is assigned on the basis of: (i) the clinical symptoms of angioedema, in the absence of significant wheals; (ii) the presence of a HAEnC1 causing variant or the existence of affected family members; and (iii) normal $\mathrm{C} 1$ inhibitor activity and $\mathrm{C} 1$ inhibitor protein levels in plasma.

The main strategy for the detection of F12 variants is the direct sequencing of an amplified PCR product of exon 9 from the patient's genomic DNA (EDTA blood), including the flanking intronic sequences. In patients with no variant in exon 9, sequencing of the remaining exons and multiplex ligation-dependent probe amplification (MLPA) analysis can be considered.

\subsection{Analytical validation}

Direct sequencing of PCR products is performed in both forward and reverse directions. When a new variant is found, the pathological relevance should be demonstrated by familial segregation analysis, confirmation of the evolutionary conservation of the affected amino $\operatorname{acid}(\mathrm{s})$, assessment of pathogenicity by mutation prediction software, and/or functional studies.

\footnotetext{
${ }^{1}$ Center for Rare Diseases Bonn, University Hospital of Bonn, Bonn, Germany; ${ }^{2}$ Institute of Human Genetics, University of Bonn School of Medicine \& University Hospital of Bonn, Bonn,Germany; ${ }^{3}$ Department of Genomics, Life\&Brain Center, University of Bonn, Bonn, Germany; ${ }^{4}$ Division of Medical Genetics, Department of Biomedicine, University Hospital of Basel, Basel, Switzerland; ${ }^{5}$ Department of Dermatology and Allergy, Comprehensive Allergy Center Charité, Charité Universitätsmedizin Berlin, Berlin, Germany ${ }^{*}$ Correspondence: Professor MM Nöthen, Institute of Human Genetics, University Hospital of Bonn, Sigmund-Freud-Str. 25, Bonn 53127, Germany. Tel: +49 (0)228 28751101 ; Fax: +49 (0)228 287 51011; E-mail: markus.noethen@uni-bonn.de Received 10 October 2016; revised 12 April 2017; accepted 23 May 2017; published online 5 July 2017
} 
1.8 Estimated frequency of the disease

(Incidence at birth ("birth prevalence") or population prevalence. If known to be variable between ethnic groups, please report):

Clinical experience suggests that population prevalence is low, although no systematic data are available. Haplotype studies of the most prevalent p.Thr328Lys variant in families from various countries have suggested a common founder, and this may well result in population differences. However, no data are available concerning prevalences in specific populations.

\subsection{Diagnostic setting}

A. (Differential) diagnostics

Yes No

B. Predictive testing

$\bigotimes$

C. Risk assessment in relatives

D. Prenatal

Comment: Mutation analysis is mainly used to confirm a clinical diagnosis and in relation to genetic counseling. In principle, prenatal diagnosis is possible. However, due to the episodic nature of the illness, the substantial clinical variability, the reduced penetrance, and the availability of therapeutic options, prenatal diagnosis is typically not requested. To date, prenatal diagnosis of HAEnC1 has not been reported.

\section{TEST CHARACTERISTICS}

\begin{tabular}{|c|c|c|c|c|}
\hline & \multicolumn{2}{|c|}{ Genotype or disease } & \multirow{2}{*}{$\begin{array}{l}\text { A: True positives } \\
\text { B: False positives }\end{array}$} & \multirow{2}{*}{$\begin{array}{l}\text { C: False negatives } \\
\text { D: True negatives }\end{array}$} \\
\hline & Present & Absent & & \\
\hline \multicolumn{5}{|l|}{ Test } \\
\hline \multirow[t]{2}{*}{ Positive } & $A$ & B & Sensitivity: & $A /(A+C)$ \\
\hline & & & Specificity: & $\mathrm{D} /(\mathrm{D}+\mathrm{B})$ \\
\hline \multirow[t]{2}{*}{ Negative } & C & $\mathrm{D}$ & Positive predictive value: & $A /(A+B)$ \\
\hline & & & Negative predictive value: & $\mathrm{D} /(\mathrm{C}+\mathrm{D})$ \\
\hline
\end{tabular}

\subsection{Analytical sensitivity}

(proportion of positive tests if the genotype is present)

If one of the four known variants in exon 9 of F12 is present, the sensitivity for Sanger sequencing of genomic DNA is almost $100 \%$. To date, sequencing of patients with no variant in exon 9 has failed to identify variants in other regions of the gene. ${ }^{13}$ However, deep intronic variants, large deletions, and duplications would not be detected using this approach. Linkage studies have identified families with no linkage to the F12 locus, ${ }^{1}$ and thus other causative gene(s) must exist. However, no other causative gene has yet been identified.

\subsection{Analytical specificity}

(proportion of negative tests if the genotype is not present)

Close to $100 \%$.

\subsection{Clinical sensitivity}

(proportion of positive tests if the disease is present) The clinical sensitivity can be dependent on variable factors such as age or family history. In such cases a general statement should be given, even if a quantification can only be made case by case.

Clinical sensitivity is dependent on clinical presentation and family history. In investigations of large cohorts of patients with familyhistory positive HAEnC1, ${ }^{22}$ approximately $25-33 \%$ of patients carried a variant in $F 12 .{ }^{12,13,23}$

\subsection{Clinical specificity}

(proportion of negative tests if the disease is not present)

The clinical specificity can be dependent on variable factors such as age or family history. In such cases a general statement should be given, even if a quantification can only be made case by case.

Close to $100 \%$.

\subsection{Positive clinical predictive value}

(life time risk to develop the disease if the test is positive)

For $F 12$ variant carriers, the estimated penetrance is $<10 \%$ in males and around $60 \%$ in females. ${ }^{9,15,24}$

\subsection{Negative clinical predictive value}

(Probability not to develop the disease if the test is negative). Assume an increased risk based on family history for a nonaffected person. Allelic and locus heterogeneity may need to be considered.

Index case in that family had been tested:

If the index case has been tested and a variant in F12 has been identified: $100 \%$

Due to allelic and locus heterogeneity, the relatives of an index patient with no identified $F 12$ variant remain at increased risk.

Index case in that family had not been tested:

If the index case has not been tested, a negative test result in a nonaffected relative does not exclude the presence of HAEnC1, since an undetected F12 variant may exist, and the possibility of locus heterogeneity ${ }^{12,13,23}$ and reduced penetrance remain.

\section{CLINICAL UTILITY}

3.1 (Differential) diagnostics: The tested person is clinically affected (To be answered if in 1.9 "A" was marked)

\subsubsection{Can a diagnosis be made other than through a genetic test?}

\begin{tabular}{lll}
\hline No & $\square$ (continue with 3.1.4) \\
Yes & $\bigotimes$ & $\square$ \\
& Clinically & \\
& Imaging & $\square$ \\
& Endoscopy & $\square$ \\
& Biochemistry & $\square$ \\
& Electrophysiology & $\square$ \\
& Other (please describe) & family history
\end{tabular}

Genetic testing helps to confirm the diagnosis. A clinical diagnosis of HAEnC1 is assigned on the basis of: (i) the clinical symptoms of angioedema, in the absence of significant wheals; (ii) the presence of a HAEnC1 causing variant or the existence of affected family members; and (iii) normal $\mathrm{C} 1$ inhibitor activity and $\mathrm{C} 1$ inhibitor protein levels in plasma.

\subsubsection{Describe the burden of alternative diagnostic methods to the patient}

The biochemical investigation of $\mathrm{C} 1$ inhibitor status requires blood sampling. No other invasive procedures are required to establish a clinical diagnosis. 
3.1.3 How is the cost effectiveness of alternative diagnostic methods to be judged?

Clinical investigation, evaluation of family history, and biochemical assays are used routinely in the diagnostic evaluation of patients, which is necessary in order to determine appropriate management and follow-up. Genetic testing helps to confirm the diagnosis and enables the testing of relatives.

3.1.4 Will disease management be influenced by the result of a genetic test?

\begin{tabular}{ll}
\hline No & $\square$ \\
Yes & $\square$ \\
& Therapy (please describe) \\
& Prognosis (please describe) \\
& Management (please describe)
\end{tabular}

Comment: No controlled studies of the clinical management of HAEnC1 have been published, although the presumed pathophysiology suggests potential treatment options ${ }^{22}$ and off label use has been reported. ${ }^{9,25}$ No data are available concerning differences in clinical management, treatment response, or prognosis between patients with variants in F12 (FXII-HAE) and variant-negative patients (U-HAE).

3.2 Predictive setting: The tested person is clinically unaffected but carries an increased risk based on family history (To be answered if in 1.9 "B" was marked)

If an F12 variant has been demonstrated in an affected family member, unaffected relatives can be tested for the presence of the variant.

\subsubsection{Will the result of a genetic test influence lifestyle and prevention?}

If the test result is positive (please describe). In an unaffected female relative, a positive genetic test suggests that the subject will be sensitized to known triggering factors, such as pregnancy or the use of oral contraceptives or hormone replacement therapy. In such cases, alternative contraceptive and hormone stabilization strategies should be considered. In men, the genetic test result has less influence on lifestyle and prevention, since $>90 \%$ of men with a positive genetic test remain asymptomatic, and no trigger factors have been identified in the small number of male patients reported to date. ${ }^{15}$

If the test result is negative (please describe). In women, a negative test result will also impact lifestyle, since no episodes of angioedema are anticipated in such cases. A negative result will therefore provide psychological relief for the female family members of affected patients.

3.2.2 Which options in view of lifestyle and prevention does a person at-risk have if no genetic test has been done (please describe)?

For the first-degree relatives of a confirmed F12 variant carrier, the $a$ priori risk of carrier status is $50 \%$. Women in particular may consider adapting their lifestyle to their potential at-risk status as a preventive measure.

3.3 Genetic risk assessment in family members of a diseased person (To be answered if in 1.9 "C" was marked).

3.3.1 Does the result of a genetic test resolve the genetic situation in that family?

Yes.

3.3.2 Can a genetic test in the index patient save genetic or other tests in family members?

Yes, if no established or novel variant in the F12 gene is detected in the index patient.
3.3.3 Does a positive genetic test result in the index patient enable a predictive test in a family member?

Yes.

3.4 Prenatal diagnosis (To be answered if in 1.9 "D" was marked) 3.4.1 Does a positive genetic test result in the index patient enable a prenatal diagnosis?

Yes.

\section{IF APPLICABLE, FURTHER CONSEQUENCES OF TESTING}

Please assume that the result of a genetic test has no immediate medical consequences. Is there any evidence that a genetic test is nevertheless useful for the patient or his/her relatives? (Please describe) Not applicable.

\section{CONFLICT OF INTEREST}

The authors declare no conflict of interest.

\section{ACKNOWLEDGEMENTS}

This work was supported by EuroGentest2 (Unit 2: "Genetic testing as part of health care"), a Coordination Action under FP7 (Grant Agreement Number 261469) and the European Society of Human Genetics.

1 Cichon S, Martin L, Hennies HC et al: Increased activity of coagulation factor XII (Hageman factor) causes hereditary angioedema type III. Am J Hum Genet 2006; 79: 1098-1104.

2 Dewald G, Bork K: Missense mutations in the coagulation factor XII (Hageman factor) gene in hereditary angioedema with normal C1 inhibitor. Biochem Biophys Res Commun 2006; 343: 1286-1289.

3 Picone O, Donnadieu AC, Brivet FG, Boyer-Neumann C, Frémeaux-Bacchi V, Frydman $\mathrm{R}$ : Obstetrical complications and outcome in two families with hereditary angioedema due to mutation in the F12 gene. Obstet Gynecol Int 2010; 2010: 957507.

4 Baeza ML, Rodríguez-Marco A, Prieto A, Rodriguez-Sainz C, Zubeldia JM, Rubio M: Factor XII gene missense mutation Thr328Lys in an Arab family with hereditary angioedema type III. Allergy 2011; 66: 981-982.

5 Bell CG, Kwan E, Nolan RC, Baumgart KW: First molecular confirmation of an Australian case of type III hereditary angioedema. Pathology 2008; 40: 82-83.

6 Stieber C, Grumach AS, Cordeiro E et al: First report of a FXII gene mutation in a Brazilian family with hereditary angio-oedema with normal C1 inhibitor. Br J Dermatol 2015; 173: 1102-1104

7 Nagy N, Greaves MW, Tanaka A, McGrath JA, Grattan CE: Recurrent European missense mutation in the $\mathrm{F} 12$ gene in a British family with type III hereditary angioedema. J Dermatol Sci 2009; 56: 62-64.

8 Martin L, Raison-Peyron N, Nöthen MM, Cichon S, Drouet C: Hereditary angioedema with normal $\mathrm{C} 1$ inhibitor gene in a family with affected women and men is associated with the p.Thr328Lys mutation in the F12 gene. J Allergy Clin Immunol 2007; 120: 975-977.

9 Vitrat-Hincky V, Gompel A, Dumestre-Perard C et al: Type III hereditary angio-oedema: clinical and biological features in a French cohort. Allergy 2010; 65: 1331-1336.

10 Bork K, Wulff K, Hardt J, Witzke G, Staubach P: Hereditary angioedema caused by missense mutations in the factor XII gene: clinical features, trigger factors, and therapy. J Allergy Clin Immunol 2009; 124: 129-134.

11 Duan QL, Binkley K, Rouleau GA: Genetic analysis of factor XII and bradykinin catabolic enzymes in a family with estrogen-dependent inherited angioedema. J Allergy Clin Immunol 2009; 123: 906-910.

12 Mansi M, Zanichelli A, Coerezza A et al: Presentation, diagnosis and treatment of angioedema without wheals: a retrospective analysis of a cohort of 1058 patients. Intern Med 2015; 277: 585-593.

13 Firinu D, Bafunno V, Vecchione $\mathrm{G}$ et al: Characterization of patients with angioedema without wheals: the importance of F12 gene screening. Clin Immunol 2015; 157 239-248.

14 Prieto A, Tornero P, Rubio M, Fernández-Cruz E, Rodriguez-Sainz C: Missense mutation Thr309Lys in the coagulation factor XII gene in a Spanish family with hereditary angioedema type III. Allergy 2009; 64: 284-286.

15 Marcos C, López Lera A, Varela, Liñares T, Alvarez-Eire MG, López-Trascasa M: Clinical, biochemical, and genetic characterization of type III hereditary angioedema in 13 Northwest Spanish families. Ann Allergy Asthma Immunol. 2012; 109: 195-200.

16 Gómez-Traseira C, López-Lera A, Drouet C et al: Hereditary angioedema caused by the p.Thr309Lys mutation in the F12 gene: a multifactorial disease. J Allergy Clin Immunol 2013; 132: 986-989. 
17 Björkqvist J, de Maat S, Lewandrowski U et al: Defective glycosylation of coagulation factor XII underlies hereditary angioedema type III. J Clin Invest 2015; 125: 3132-3146.

18 De Maat S, Björkqvist J, Suffritti $\mathrm{C}$ et al: Plasmin is a natural trigger for bradykinin production in patients with hereditary angioedema with factor XII mutations. J Allergy Clin Immunol 2016; 138: 1414-1423.

19 Bork K, Wulff K, Meinke P, Wagner N, Hardt J, Witzke G: A novel mutation in the coagulation factor 12 gene in subjects with hereditary angioedema and normal C1inhibitor. Clin Immunol 2011; 141: 31-35.

20 Citarella F, Ravon DM: Structure/function analysis of human factor XII using recombinant deletion mutants. Evidence for an additional region involved in the binding to negatively charged surfaces. Eur J Biochem 1996; 238: 240-249.
21 Kiss N, Barabás E, Várnai K et al: Novel duplication in the F12 gene in a patient with a recurrent angioedema. Clin Immunol 2013; 149: 142-145.

22 Cicardi M, Aberer W, Banerji A et al: Classification, diagnosis, and approach to treatment for angioedema: consensus report from the Hereditary Angioedema International Working Group. Allergy 2014; 69: 602-616.

23 Bork K, Wulff K, Witzke G, Hardt J: Hereditary angioedema with normal C1-INH with versus without specific F12 gene mutations. Allergy 2015; 70: 1004-1012.

24 Bork K, Gül D, Hardt J, Dewald G: Hereditary angioedema with normal C1 inhibitor: clinical symptoms and course. Am J Med 2007; 120: 987-992.

25 Bork K, Wulff K, Witzke G, Hardt J: Treatment for hereditary angioedema with normal $\mathrm{C} 1-\mathrm{INH}$ and specific mutations in the F12 gene (HAE-FXII). Allergy 2017; 72: 320-324. 